\title{
Stage IVB Bone Sarcoma AJCC v7
}

National Cancer Institute

\section{Source}

National Cancer Institute. Stage IVB Bone Sarcoma AJCC v7. NCI Thesaurus. Code C6708.

Stage IVB includes: (Any T, N1, Any M, Any G); (Any T, Any N, M1 b, Any G). N1: Regional lymph node metastasis. M1b: Metastasis to other distant sites. (AJCC 7th ed.) 